\title{
Are soybean yields getting a free ride from climate change? Evidence from Argentine time series
}

\author{
Hildegart Ahumada ${ }^{\dagger}$ \\ Universidad Torcuato Di Tella
}

\author{
Magdalena Cornejo ${ }^{\ddagger}$ \\ Universidad Torcuato Di Tella and CONICET
}

\begin{abstract}
Soybean yields are often indicated as an interesting case of climate change mitigation due to the beneficial effects of $\mathrm{CO}_{2}$ fertilization. In this paper we econometrically study this effect using a time series model of yields in a multivariate framework for a main producer and exporter of this commodity, Argentina. We have to deal with the upward behavior of soybean yields trying to identify which variables are the long-run determinants responsible of its observed trend. With this aim we adopt a partial system approach to estimate subsets of long-run relationships due to climate, technological and economic factors. Using an automatic selection algorithm we evaluate encompassing of the different obtained equilibrium correction models. We found that only technological innovations due to new crop practices and the use of modified seeds explain soybean yield in the long run. Regarding short run determinants we found positive effects associated with the use of standard fertilizers and also from changes in atmospheric $\mathrm{CO}_{2}$ concentration which would suggest a mitigation effect from global warming. However, we also found negative climate effects from periods of droughts associated with La Niña episodes, high temperatures and extreme rainfall events during the growing season of the plant.
\end{abstract}

Keywords: climate change; soybean yields; technology; temperature; $\mathrm{CO}_{2}$.

\footnotetext{
${ }^{\dagger}$ Corresponding author. School of Government, Universidad Torcuato Di Tella. Av. Figueroa Alcorta 7350, Buenos Aires, Argentina. E-mail address: hahumada@utdt.edu.

$\ddagger$ School of Government, Universidad Torcuato Di Tella. Av. Figueroa Alcorta 7350, Buenos Aires, Argentina. E-mail address: mcornejo@utdt.edu.
} 


\section{Introduction}

Due to its strong dependence on climatic variables, the effects of climate changes on agriculture have been deeply studied. In particular, world food production has been a matter of global concern, particularly for less developed economies as outlined in the Stern Review. However, as Nordhaus (2013) suggests (based on the IPCC 4th Assessment Report) it is especially in the agricultural sector where the adaptation and mitigation processes have been taking place. These processes are mainly driven by technological developments or managerial changes such as the displacement of crop areas, replacing those most affected by global warming with "modest warming" areas and the incorporation of new technology (e.g. the use of seeds more resistant to climate variability or pesticides).

Moreover, for several agricultural products the $\mathrm{CO}_{2}$ emissions, the main responsible for climate change and global warming, are indicated as having an important mitigation effect on crop yields due to fertilizer properties. In particular, it is extremely relevant for soybeans yields given it is usually pointed out as a case of increasing yields associated with the fortuitously beneficial effects of $\mathrm{CO}_{2}$ atmospheric concentrations. According to Nordhaus (2013) multiple field studies found that doubling atmospheric concentrations of $\mathrm{CO}_{2}$ would increase yields of rice, wheat and soybeans 10-15 percent. For the Argentine case, the third worldwide largest producer and exporter of soybeans, Magrin et al. (2005) using agronomic models found that changes in yields corresponding to climate changes between 1930-60 and 1970-2000 were $38 \%$ for this crop.

In this paper we econometrically study the time series behaviour of soybean yields in Argentina in order to understand and measure the effect of global climate change on them, including in particular the mitigation effects driven by $\mathrm{CO}_{2}$ along with other factors such as managerial changes and technology. It is worth noting that to address the $\mathrm{CO}_{2}$ fertilization effect, it is $\mathrm{CO}_{2}$ global concentration that should have a local impact by improving crop yields. Furthermore, we should take into account other determinants of crop yields like variables reflecting technological developments and economic factors such as product and inputs prices.

To achieve this goal, we follow a partial system approach as discussed in Juselius (2006, ch. 19). One of the advantages of this approach is that it allows us to deal with collinearities, a main issue when variables show trending behavior ${ }^{1}$ and also to evaluate exogeneity. We estimate subsets of long-run relationships due to climate, technological and economic factors. Using an automatic selection algorithm, Autometrics, we evaluate encompassing of the different equilibrium correction models obtained from the partial systems.

\footnotetext{
${ }^{1}$ The question of trend removal is a key issue as discussed by Lobell and Burke (2010).
} 
Our findings provide evidence that only technology innovations explain yields in the long run and carbon fertilization would have short run effects along with climate variables measured by La Niña episodes and local high temperatures.

The paper is organised as follows. Section 2 discusses different approaches to modelling crop yields that have been suggested in the literature. Section 3 describes our data. Section 4 explains the econometric methodology. Section 5 presents our main results for the long run from the partial system approach, shows the estimates of the selected equilibrium correction model with the main determinants and discusses the main findings. The last section concludes.

\section{Different approaches to modelling crop yields}

Since the pioneering works of Smith (1914) and Fisher (1925), an extensive empirical literature has been trying to statistically estimate the effects of climatic variables on the agricultural sector.

The awareness of global warming, and its consequences on different fields, has renewed the interest in studying this topic during the last decade. The assessment of climate changes effects on crop yields has been a multidisciplinary topic. Economists, agronomists, meteorologists and other scientists have been largely studying the subject.

In contrast to econometric studies, many of the agronomic analyses focus on estimating the effect of climate on crops yields from models based on controlled experiments that require greater insights of the plant physiology, climate conditions and soil properties. However, the usefulness of these models is limited because they only incorporate physical aspects of potential yield and typically do not consider technological and global factors that allow yields to change over time.

Crop simulation models are also widely used in the meteorology field to predict crop production and yields in studies of the climate change impacts. Their calculations are based on the existing knowledge of the plant conditions and ecology of crop responses to the environment. Several other agronomic studies have modelled the effects of climate change on a wide variety of crops and areas throughout the world, but at a micro (states or counties) level.

The empirical literature shows mixed evidence of the effect of climate changes on crop yields because there would be several factors that have partially reduced the harmful impacts of climate change. Adaptation, trade, the declining share over time of agriculture in the economy and, relevant for our study, the mitigation carbon fertilization (see Nordhaus 2013). Lobell and Burke (2010) summarize the sources of divergence among different estimated models to get a more robust picture of likely climate change impacts. They conclude that statistical models, compared to processbased models, play an important role in anticipating future impacts of climate change 
and their usefulness is higher at broader spatial scales.

Using a county-level panel on crop yields, Chen et al. (2013) estimate the impact of climate change on corn and soybean yields in China. From different spatial panel econometrics techniques, the authors find non-linearities and asymmetric relationships between yields and weather variables as it has been previously suggested in the literature (Schlenker and Roberts 2009). Furthermore, they find that extreme high temperatures are always harmful for crop growth.

In this line, Lobell et al. (2011) study the impact of the change in climate trends on the yield of four large crops (corn, wheat, rice and soybeans, which account for $75 \%$ of the calories humans consume directly or indirectly) between 1980 and 2008 for all the countries of the world. The authors find that, at the global level, corn and wheat yields showed adverse effects for the largest producers and a net overall loss of $3.8 \%$ and $5.5 \%$, respectively. The net impact on rice and soybean production was insignificant, with gains in some countries that balanced the losses of others. In turn, most of the impacts were due to changes in temperature trends and not precipitation. This result is consistent with many recent studies of the climate change effects on yields where changes in temperature are more important than changes in rainfall, at least at the national and regional levels (Reilly and Schimmelpfennig 2000; Schlenker and Lobell 2010). Crop yield losses on the hottest days drive much of the effect of temperature (Schlenker and Roberts 2009). Furthermore, crops are more sensitive to extremely high temperatures during the phases of the growth cycle (Auffhammer et al. 2012; Welch et al. 2010).

As Auffhammer and Schlenker (2014) state, one of the greatest challenges in empirical analyses is the identification of adaptation responses to changes in climatic conditions. In this sense, the adaptation process should be evaluated as a long-term effect, but short-run responses should also be taken into account. Burke and Emerick (2016) examine the effect of long-term changes in climatic variables on yields using county-level data in the United States. Their results indicate that the main crops in the U.S., corn and soybeans, are significantly and negative affected by long-term changes in extreme heat temperatures. Changes in short-term temperature extremes can be critical, especially if they coincide with flowering stage of many crops reducing their yield (Wheeler et al. 2000).

Empirical studies should not ignore or underestimate the effects of adaptation measures as means for diminishing the adverse effects of climate change. Several adaptation measures such as shifting planting dates or developing new crop varieties have also been suggested and implemented for reducing vulnerability from the potential negative impacts of climate change on crop yield and production (Lobell et al. 2008; Cohn et al. 2016).

A more comprehensive analysis of yield determinants is provided by Huang and 
Khanna (2010). They estimate a model using county panel data including climate variables along with output and input prices and technology measured as irrigated lands and deterministic trends.

Given the above literature and the importance of considering a multivariate framework, we suggest an econometric approach that tries to encompass different groups of drivers that affect crop yields which can be organized as in Figure 1 and are discussed in sections 3 and 4 .

Figure 1. Different determinants of soybean yields

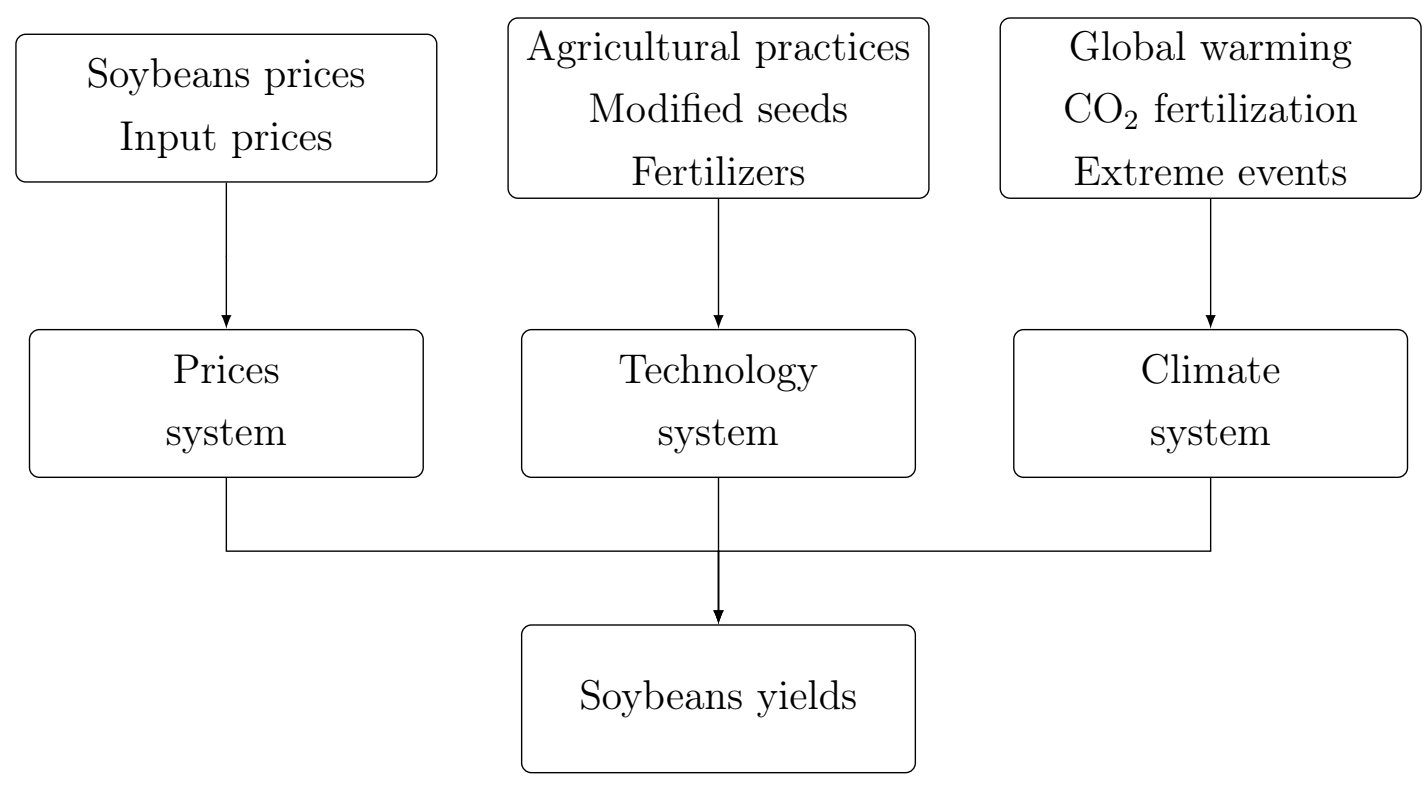

\section{Data description}

Our dataset consists of annually series over a period spanning from 1973 to 2015 $(T=43)$. The initial period is due not only to data availability but also because it is in the early 70's when soybeans start to be a significant crop in Argentina. Table 1 reports the variables descriptions and sources. 
Table 1: Data description

\begin{tabular}{|c|c|c|c|}
\hline Symbol & Description & Units & Source \\
\hline$y$ & Soybean yield & $\mathrm{kg} / \mathrm{ha}$ & FAO \\
\hline cropland & Arable Land + Land in Permanent Crops & ha & USDA \\
\hline irrigation & Area equiped for irrigation & ha & USDA \\
\hline labour & $\begin{array}{l}\text { Agricultural labor, } 1000 \text { persons economically ac- } \\
\text { tive in agriculture }\end{array}$ & units & USDA \\
\hline machinery & Number of 40 CV Tractor-Equivalents in use & units & USDA \\
\hline fertilizer & $\begin{array}{l}\text { Fertilizer consumption, first principal component } \\
\text { of } \mathrm{N}, \mathrm{P}_{2} \mathrm{O}_{5} \text { and } \mathrm{K}_{2} \mathrm{O}\end{array}$ & tonnes & IFA \\
\hline agriland & Agricultural land & $\%$ & FAO \\
\hline $\mathrm{CO}_{2}$ & $\begin{array}{l}\text { Mean atmospheric carbon dioxide at Mauna Loa } \\
\text { Observatory, Hawaii }\end{array}$ & ppm & NOAA \\
\hline temp & Global annual temperature anomalies & ${ }^{\circ} \mathrm{C}$ & CDIAC \\
\hline $\max 28$ & $\begin{array}{l}\text { Number of days during growing season with max- } \\
\text { imum temperature above } 28^{\circ} \mathrm{C}\end{array}$ & days & SMN \\
\hline $\max 29$ & $\begin{array}{l}\text { Number of days during growing season with max- } \\
\text { imum temperature above } 29^{\circ} \mathrm{C}\end{array}$ & days & SMN \\
\hline $\max 30$ & $\begin{array}{l}\text { Number of days during growing season with max- } \\
\text { imum temperature above } 30^{\circ} \mathrm{C}\end{array}$ & days & SMN \\
\hline $\max 31$ & $\begin{array}{l}\text { Number of days during growing season with max- } \\
\text { imum temperature above } 31^{\circ} \mathrm{C}\end{array}$ & days & SMN \\
\hline$C V$ & Precipitation coefficient of variation & $\%$ & SMN \\
\hline$P C I$ & Precipitation concentration index & $\%$ & SMN \\
\hline$R G I$ & Rainfall Gini Index & index & SMN \\
\hline$A D$ & $\begin{array}{l}\text { Precipitation absolute deviations with respect to } \\
\text { the historical mean }\end{array}$ & $\mathrm{mm}$ & SMN \\
\hline$A D 1 S E$ & $\mathrm{AD} \pm$ one standard error & $\mathrm{mm}$ & SMN \\
\hline$A D 2 S E$ & $\mathrm{AD} \pm$ two standard errors & $\mathrm{mm}$ & SMN \\
\hline$N i \widetilde{n} a$ & Niña events & dummy & BOM \\
\hline$N i \widetilde{n} o$ & Niño events & dummy & BOM \\
\hline notill & Proportion of no tilled cropland acres & ratio & AAPRESID \\
\hline seeds & $\begin{array}{l}\text { Number of soybean seeds registered in Argentina, } \\
\text { Brazil and United States }\end{array}$ & units & $\begin{array}{l}\text { INASE, SRNC } \\
\text { \& USDA }\end{array}$ \\
\hline$p^{\text {fertilizer }}$ & $\begin{array}{l}\text { Weighted average of natural phosphate rock, } \\
\text { phosphate, potassium, and nitrogenous prices. } \\
\text { Based on current US dollars }\end{array}$ & $2010=100$ & World Bank \\
\hline$p^{\text {soybean }}$ & Soybean prices. Based on current US dollars & $2010=100$ & World Bank \\
\hline
\end{tabular}

Demand for oilseeds, and particularly soybeans, has rapidly increased during the last decades. It is one of the most valuable crops in the world, not only because of its use as oil seed but also as high-protein meal for animal and human feed as well as a source for biofuel production. In Argentina, the third worldwide largest producer of soybeans, production increased by $2 \%$ annually from 1973 to 2015. Average soybean yield (measured as kilogram per hectare, $\mathrm{kg} / \mathrm{ha}$ ) increased from 1,732 kg/ha in 1973 to $3,174 \mathrm{~kg} / \mathrm{ha}$ in 2015 . During the sample period, climate changes and technological advances shifted the main production area to the north, to warmer latitudes. These factors, which are taken into account in our dataset, suggest that it is worth focusing on their effects on soybean yields in Argentina. 


\subsection{Climate variables}

Several global and local climate variables are considered in the analysis. It has been usually indicated that one of the best predictors of soybean yield is a measure of extreme heat during growth periods considering a temperature threshold above $29^{\circ} \mathrm{C}$ (Schlenker and Roberts, 2009). Thus, using daily data of maximum temperature from 54 meteorological stations of the soybean production area, we construct different variables that measure the number of days in a year, during the growing phase of the crop (from December to April) in which the temperature exceeded a threshold of $28^{\circ} \mathrm{C}, 29^{\circ} \mathrm{C}, 30^{\circ} \mathrm{C}$ or $31^{\circ} \mathrm{C}$. Therefore, we evaluate which of these different thresholds is significant for Argentine soybean yields. The maximum temperature data was obtained from the National Weather Service. The maximum temperature of each meteorological station was weighted by its share in the total soybean planted area. Those weights were annually updated to account for the displacement of crop areas over time. This variable allows us to capture non-linearities in the relationships between yield and local temperature as it has been suggested in the literature.

Another weather influence on crop yields is precipitation. Unfavorable weather conditions during the growing season of the plant may threaten soybean yields. Water stress during flower induction and flowering may affect seed weight, resulting in large seed weight variations. We used the daily precipitation data from the same meteorological stations in the soybean production area, as descripted above, to evaluate different measures of excess or lack of precipitation. We restricted our analysis to the R3 and R4 reproductive soybean growth stages. During those stages, the plant reaches the full pod stage and the seed development begins. Those stages mainly occur during January and February in the main soybean area of Argentina. The different measures of precipitation variability include: the coefficient of variation $(C V)$, the precipitation concentration index $(P C I)$, the rainfall gini index (RGI), the absolute deviations with respect to the historical mean $(A D)$, the $\mathrm{AD}$ plus and minus one standard error $(A D 1 S E)$, and the AD plus and minus two standard erros $(A D 2 S E)$.

Also, el Niño and La Niña events in the Pacific Ocean were identified through the Southern Oscillation Index (SOI). The SOI, obtained from the Australian Bureau of Meteorology (BOM), is calculated using the pressure differences between Tahiti and Darwin. Sustained negatives values of SOI below -7 indicate El Niño episodes, while sustained positives values of SOI above +7 indicate La Niña episodes (see Figure 2). El Niño and La Niña events are respectively associated to floods and droughts in southeastern South America.

We also consider a measure of global warming: the global temperature anomalies computed from land and ocean data as the temperature differences (in ${ }^{\circ} \mathrm{C}$ ) relative to the 1951-1980 base period means reported by the GISTEMP team of the Carbon 
Dioxide Information Analysis Center (CDIAC). During our sample period, the global temperature anomalies showed a steady increase from a minimum of $-0.81{ }^{\circ} \mathrm{C}$ in 1974 to a maximum of $0.86{ }^{\circ} \mathrm{C}$ by 2015 .

Figure 2. Number of days during the growing season with temperatures above $30^{\circ} \mathrm{C}$ and El Niño and La Niña events.

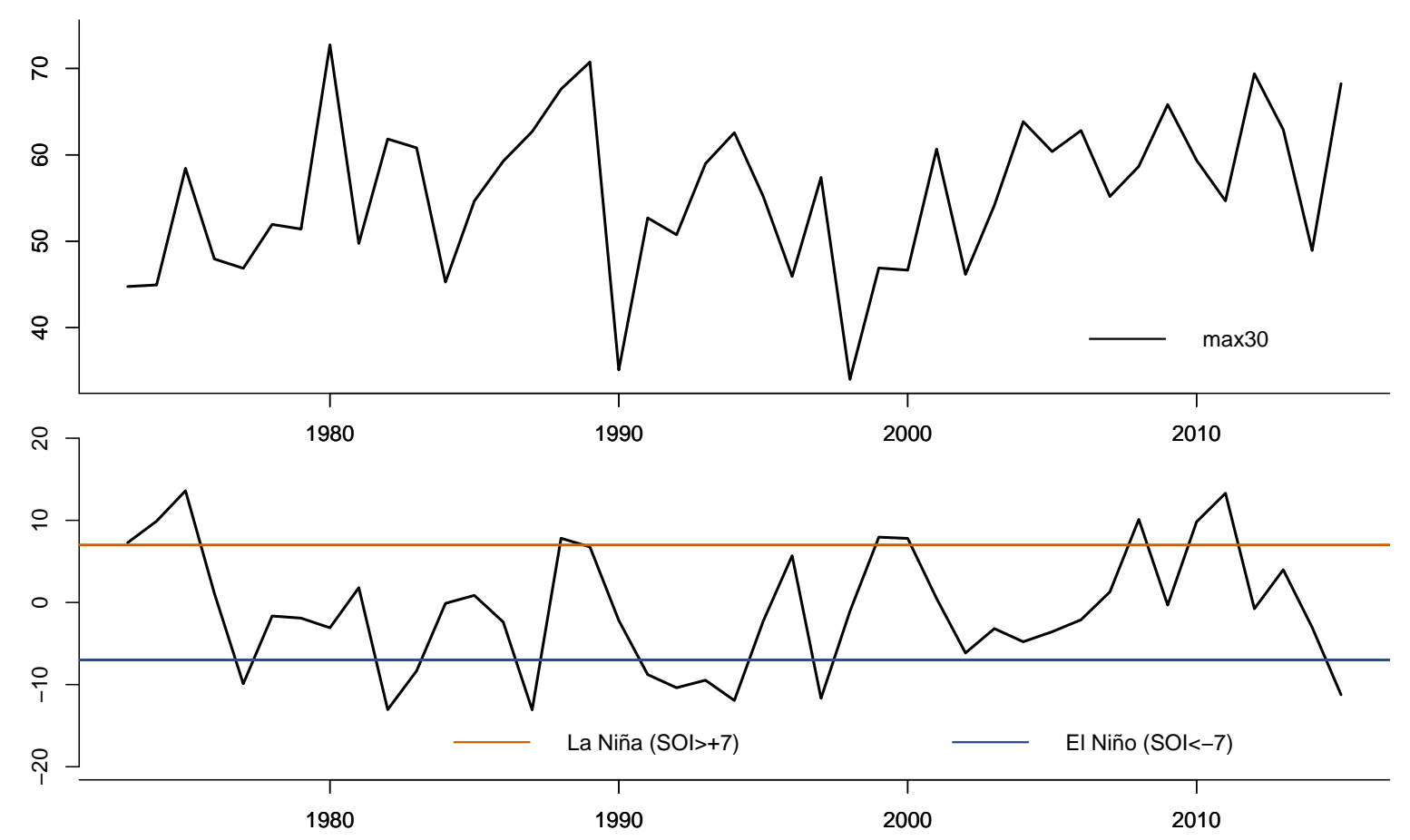

The largest amount of carbon dioxide $\left(\mathrm{CO}_{2}\right)$ in the atmosphere that has resulted from rising anthropogenic emissions may have positive effects on the plants growth as plants use carbon dioxide during photosynthesis. This effect is known as the carbon fertilization effect, the phenomenon by which the increase of carbon dioxide in the atmosphere increases the rate of photosynthesis in plants. Carbon fertilization has a greater effect on plants with $\mathrm{C}_{4}$ and $\mathrm{C}_{3}$ photosynthesis systems (such as corn and soybeans, respectively), which can concentrate carbon dioxide onto reaction sites. However, this effect may not take place as nutrient levels, soil moisture, water availability and other conditions must also be met. Using an eight-year study to simulate $\mathrm{C}_{3}$ crop yield by rising concentrations of atmospheric carbon dioxide, Gray et al. (2016) found that the intensification of drought eliminates the potential benefits of elevated dioxide for soybean.

Figure 3 shows the evolution of soybean yields, global temperature anomalies and the globally average $\mathrm{CO}_{2}$ concentration at the surface during the analysed period. 
Figure 3. Argentine soybean yield and global climate variables
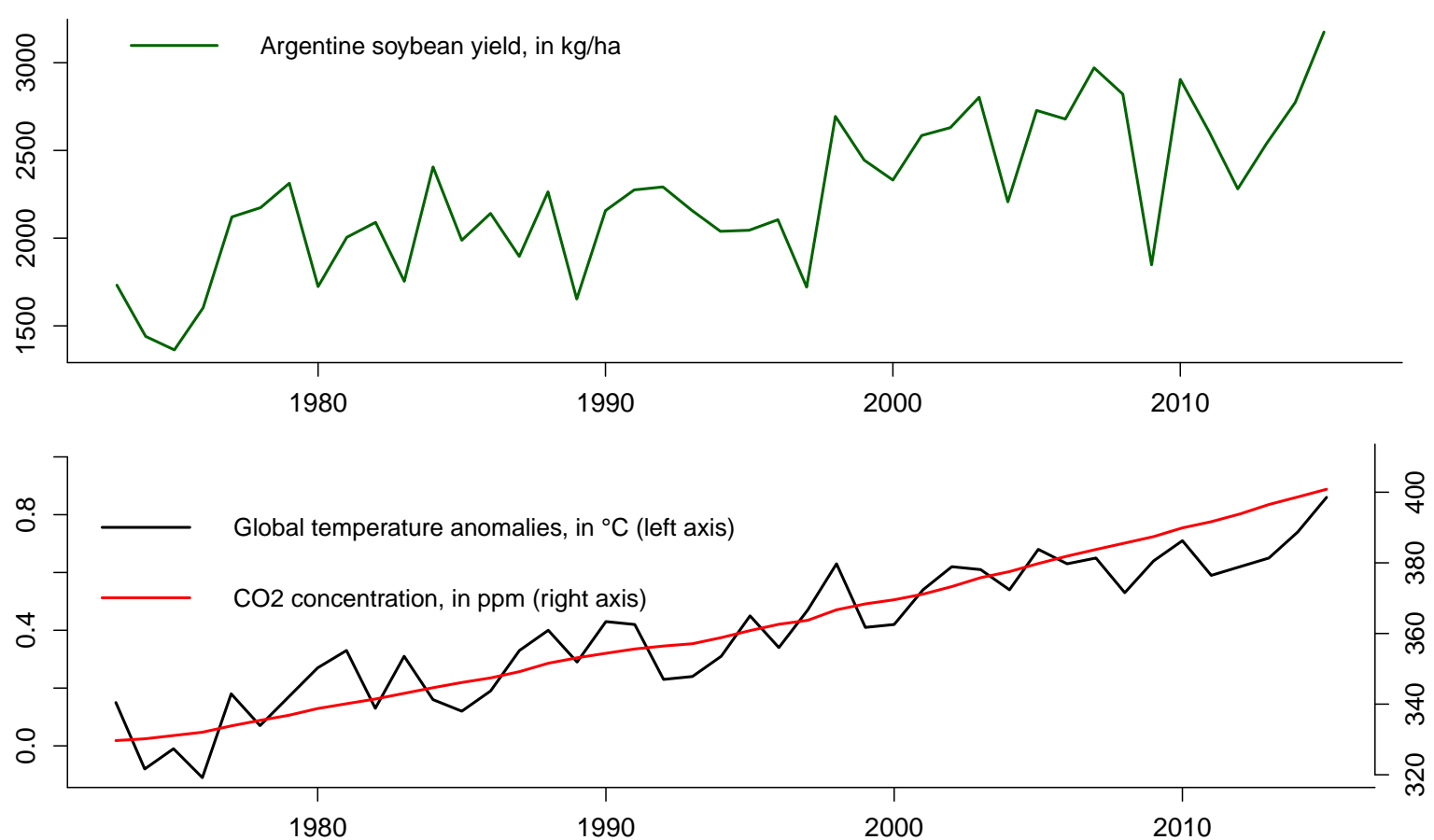

\subsection{Other potential determinants of soybean yields}

As stated before, to evaluate the effect of climate change on crop yields and, in particular, the $\mathrm{CO}_{2}$ fertilization effect, we should also control for other determinants such as technological innovations and prices.

In our estimations, we also considered the consumption of different fertilizers, that is, the use of inorganic manufactured products that supply plant nutrients as a possible driver of the soybean yield increase during the last fifty years. Soybean plants usually have high requirement for phosphorus $\left(\mathrm{P}_{2} \mathrm{O}_{5}\right)$, potassium $\left(\mathrm{K}_{2} \mathrm{O}\right)$ and, in a lesser extent, nitrogen $(\mathrm{N})$. Therefore, in order to have an aggregate measure of fertilizer use and to control for their high collinearities (as shown in Figure 4), we have conducted a principal component analysis among the consumption of these three fertilizers and obtained the first principal component, which accounted for $96.94 \%$ of the data variability. This principal component is then incorporated in our models as a measure of fertilizer aggregate consumption in soybeans production.

To assess the effect of changes in managerial practices, we included the evolution of no till practices. No till has gained ground quickly in Argentina as an effective solution to the problem of soil erosion. According to AAPRESID, the Argentine No till Farmers Association, $70 \%$ of no till farming growth was exponential with values of $90 \%$ of surface under no-till by 2014-15. Furthermore, $70 \%$ of the surface under no-till was covered by soybean in the season 2012-13 (Nocelli Pac 2017).

The use of new modified seeds was also considered in our analysis through the num- 
ber of soybean varieties registered in United States, Brazil and Argentina (the three main worldwide producers of soybeans). This variable intends to capture the transfer of knowledge across the main soybean producer countries from the adoption of genetically modified (GM) crops. Soybean remains the most adopted GM crop, according to the International Service for the Acquisition of Agri-biotech Applications (ISAAA) ${ }^{2}$ biotech soybean accounted for $50 \%$ of all the biotech crop area in the world in 2016 . Commercially grown GM soybeans are concentrated in a few countries, mainly USA, Brazil and Argentina. Figure 4 shows the marked trend for many of the technological variables.

Figure 4. Technological variables evolution

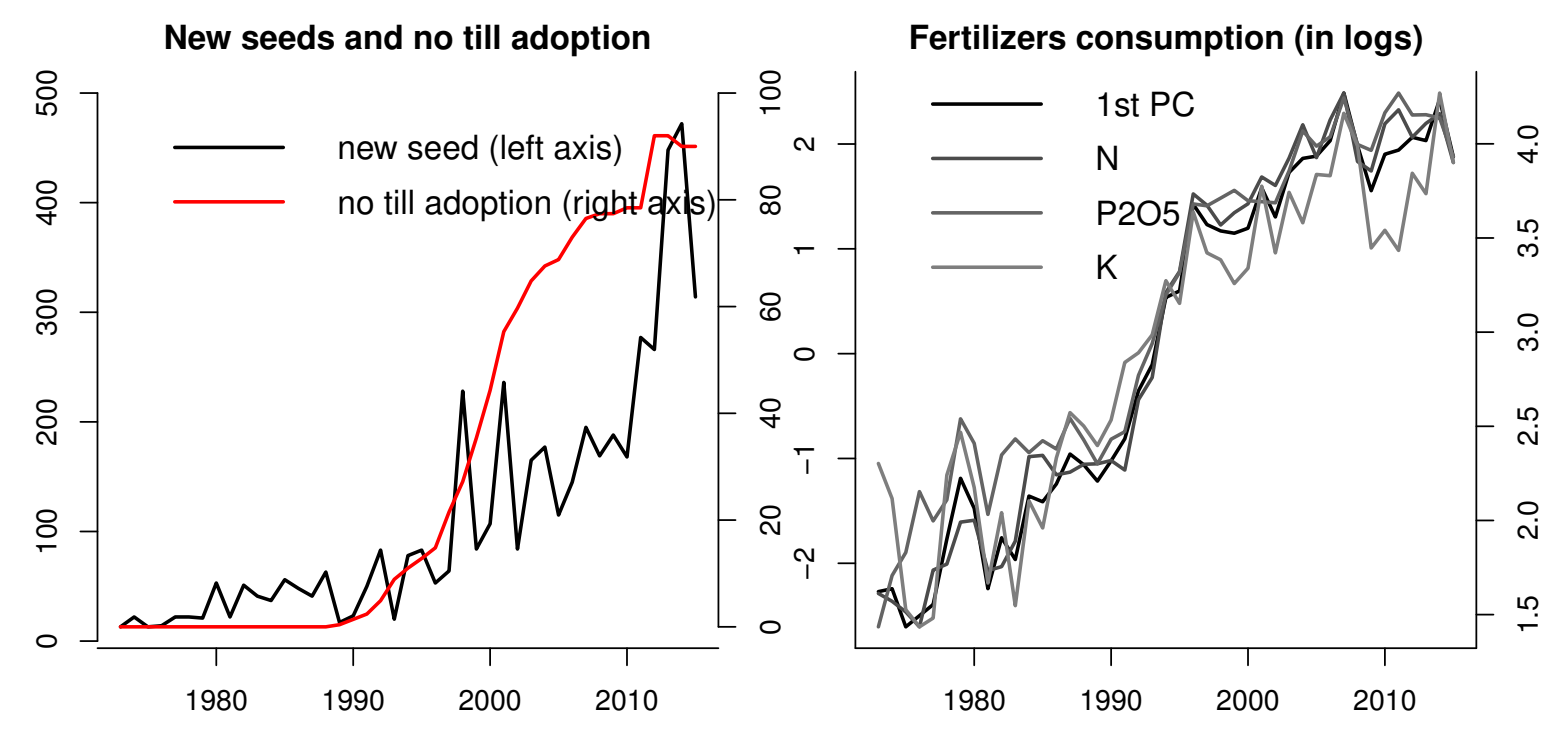

Other input factors we included, but resulted not significant, were the agricultural and irrigated land, machinery use and agricultural labor.

Finally, our dataset also includes prices to address the elasticity of soybean yield response with respect to expected output prices and fertilizer prices (as input prices).

\section{Econometric methodology}

Because of their large collinearity among the variables described in the previous section, we adopt a cointegration approach working with partial systems. This approach was first implemented by Juselius (1992) to model inflation considering the complicated relationships from the different markets by analyzing labor, external and money markets as separated systems. From the estimation of the systems, differ-

${ }^{2}$ ISAAA. 2016. Global Status of Commercialized Biotech/GM Crops: 2016. ISAAA Brief No. 52. ISAAA: Ithaca, New York. 
ent equilibrium relationships were obtained and their deviations were used to explain inflation dynamics (see also Hendry 2001; Brouwer and Ericsson 1998).

A great advantage of this approach is the invariance of the cointegration property to the extension of the information set (see Juselius 2006, ch. 19). This means that once cointegration is found among a set of variables, the cointegration results will remain valid if more variables are added to the system. This model is also designed to distinguish between influences that move equilibria (pushing forces) and influences that correct deviations from equilibrium (pulling forces) which give rise to long-run relations. After determining the cointegration rank, the significance of adjustment coefficients gives us information about which variables adjust and thereby weak exogenity can be tested by zero restrictions in the respective coefficient.

For soybean yields we start by estimating three different systems from Figure 1 (named as climate, technological, and relative prices) starting from VAR models with two lags. Given that the variables may grow at different rates we initially include a trend in the cointegration space and if not significant its effect is restricted to zero. All variables are expressed in logs, with the exception of global temperature anomalies $\left(\right.$ temp), the number of days with maximum temperatures above $30^{\circ} \mathrm{C}(\max 30)$ and the ratio of no tillage adoption (no till). We have also included other maximum temperature thresholds $\left(28^{\circ} \mathrm{C}, 29^{\circ} \mathrm{C}\right.$ and $\left.31^{\circ} \mathrm{C}\right)$, but $\max 30$ proved to be the most significant. La Niña events $(N i \tilde{n} a)$ and $\max 30$ are unrestrictedly included in the climate system as they are stationary and the first one has a similar behavior to impulse dummies. We have also tested for other climate variables such as El Niño events and weather variables associated with excessive precipitations and floods, but they were found statistically insignificant.

It should be noted that most of the series used in the systems, in particular soybean yields, can be represented as stationary around a deterministic linear trend. Because of that many studies removes deterministic trends before studying the effects of climate factors on yields (see for example Thomasz et al. 2016, in the Argentine case). However, given that our aim is to understand which variable could be behind this observed trending behavior, we study their long run relationships assuming them as integrated of first order and studying cointegration by Johansen approach. As Juselius (2006, p. 18) assesses "the order of integration of a variable is not in general a property of an economic variable but a convenient statistical approximation to distinguish between the short run, medium run and long run variation in the data".

The consistent estimates of the different long run relationships were used to estimate an equilibrium correction (EC) model of soybean yields nesting the EC terms of each $(j)$ partial system along with several short run determinants from our information set. That is, for the log differences of soybean yields $\left(\Delta y_{t}\right)$, the estimated equation is: 


$$
\Delta y_{t}=\gamma-\sum_{j=1}^{n} \alpha_{j}\left[y_{t-1}-\beta_{j}^{\prime} x_{j t-1}\right]+\sum_{k=1}^{2} \rho_{k} \Delta y_{t-k}+\sum_{k=0}^{1} \lambda^{\prime} \Delta w_{t}+\varepsilon_{t}
$$

where $j=1, \ldots, n$; indicates each if the partial systems. The vector $x_{j}$ denotes the variables that enter each $j$ partial system; $\alpha_{j}$ and $\beta_{j}$ denote the adjustment coefficients and long run coefficient for the $j$ partial system, respectively. We considered up to $k=1$ lag for the $w$ variables entering the short run, expressed as differences. ${ }^{3}$

Starting from a large information set (as descripted in the previous section), we jointly evaluate many of the explanatory variables suggested in the literature that has tried to explain crop yields. To deal with such a wide range of information and to help us select the dominant congruent model and not only a best fit, we used Autometrics, an automatic model selection algorithm. This algorithm uses a tree search to discard paths, rejected as reductions of a general unrestricted initial model, and includes diagnostic testing. This automatic algorithm follows a general to specific strategy to select variables and helped us to choose the relevant variables in the last equation.

Moreover, the algorithm can be used for an encompassing evaluation as discussed by Doornik (2008) selecting the relevant model(s) from a general unrestricted model, which includes all the variables of the different models obtained. The next section describes the estimated partial systems and the encompassing evaluation of the EC models by Autometrics.

\section{Results}

In this section, we present the results obtained using the information set described in Section 3 and following the econometric approach explained in Section 4. The EC representation allows us to disentangle the long-run and short-run effects on soybean yields as described in the following sub-sections.

\section{1. $\quad$ Long-run effects}

Taking into account the different kinds of potential determinants of crop yields we estimate three partial systems of Argentine soybean yields in line with the description of Figure 1. The cointegration results and the (not rejected by our data) constrained parameter estimates are reported in the Appendix (see Table A2 to A4).

Equations (1) to (4) show the resulting long-run equations for the cases in which

\footnotetext{
${ }^{3} w$ includes $\Delta x$ as well as other stationary potential determinants. Only the contemporaneous effects were considered for the following climate variables: $\max 28, \max 29, \max 30, \max 31, C V, P C I$, $R G I, A D, A D 1 S E$ and $A D 2 S E$.
} 
the yield adjusts. Equation (1) shows the long run relationship corresponding to the climate model. Equation (2) belongs to the technology model describing the long run relationship of yields with the effects of no till adoption and the introduction of new seed varieties. Finally, Equations (3) and (4) correspond to the prices model. In all the cases, the estimated models pass all diagnostic tests at traditional levels. ${ }^{4}$

$$
\begin{aligned}
(\text { climate model }) & \ln y=-2.34 \text { temp }+11.94 \ln C O_{2} \\
(\text { technological model }) & \ln y=0.003 \text { notill }+0.05 \ln \text { seeds } \\
(\text { prices model 1) } & \ln y=1.16 \ln p^{\text {soybean }}-0.82 \ln p^{\text {fertilizer }}+0.02 t \\
(\text { prices model 2) } & \ln p^{\text {fertilizer }}=1.36 \ln p^{\text {soybean }}+0.01 t
\end{aligned}
$$

First, as much of the literature does, we focus only on climate variables (Table A2 in Appendix). A measure of global warming (global temperature anomalies) and the $\mathrm{CO}_{2}$ concentration in the atmosphere are found to be cointegrated with Argentine soybean yields. An interesting feature is that although global temperature has a negative effect, the results suggest a mitigation effect on yield associated with carbon fertilization. To analyze the magnitude of estimated coefficients we can note that in this sample period, if the temperature changes as its median value $\left(0.06^{\circ} \mathrm{C}\right)$ soybean yields will decrease about $14 \%$ in the long run. As a possible mitigation effect, yields increase near $6 \%$ as a consequence of the median percentage variations of $\mathrm{CO}_{2}$ concentrations $(0.47 \%)$ during 1973-2015.

It should be noted that in this system, not only soybeans yields adjust to deviations from the long-run relationships but also global temperature anomalies and $\mathrm{CO}_{2}$ concentrations. Although this last result may be unexpected at first sight, it may be due to the effect of deforestation. We can note that the upward trend of yields in Argentina, a behavior also shown by other main soybean producers like Brazil, could give incentives to the expansion of agriculture through the use of new lands coming from deforestation. ${ }^{5}$ South America, during our sample period, has experienced a shift of the main production area to the north, to warmer latitudes. Deforestation contributes to global climate warming since it is responsible for not compensating the anthropogenic emissions of carbon dioxide to the atmosphere. Therefore, in this sense, we could think that global temperature anomalies and $\mathrm{CO}_{2}$ emissions may also adjust to deviations from the long-run in our estimated climate system. As Pretis (2017) warns, human activity (say, through deforestation) affects local and global climate and climate change, in turn, affects human activity (say, crop yields). Empirically,

\footnotetext{
${ }^{4}$ These results are not reported but can be obtained from the authors upon request.

${ }^{5}$ Using data from NASA's Moderate Resolution Imaging Spectrometer (MODIS) on the Terra and Aqua satellites, Morton et al. (2006) have shown that in 2003, the peak year of deforestation in Matto Grosso (Brazilian state with the highest deforestation and soybean production rates), more than 20 percent of the state's forests were converted to cropland.
} 
this implies that if we want to estimate the effect of humanity (in its multiple dimensions) on climate change and vice versa, it is necessary to evaluate the exogeneity of the variables within the economic-climate system to understand these interrelations in the long-run.

Nonetheless, we have found other representations associated with factors different from climate change. A system with the main technological innovations for the crop practices is studied (Table A3 in Appendix). One long run relationship is found in which soybean yields are explained by the no till adoption measure and the introduction of new seeds, in both cases with positive effects. In this system, only soybeans yields adjust to deviations from the long run, thus, technological variables are found to be weakly exogenous.

Finally, accordingly to the prices model (Table A4 in Appendix), two different vectors are found to affect soybean yield. In the first one, the commodity price and a main variable input price -fertilizers- have the expected signs while the second vector (significant at a $6 \%$ level) indicates that there may be an additional effect on yields when there are deviations of soybean prices over fertilizer prices, which have a positive relationship between them. From the prices system we found that soybeans yields and its price adjust to deviations from the long run.

The estimated (1) to (4) equations suggest that to understand crop yields behavior in the long-run not only climate variables are important but also technological and economic factors should be taken into account. Consistent estimates of the long run effects can be obtained from this system cointegration approach.

\subsection{Short-run effects}

In consequence, we have several explanations, which may be alternative or complementary, of the long run trending behavior of soybean yields. Encompassing by automatic selection can help to discriminate long run effects while selecting other, short run, determinants. Results are presented in Table $2 .^{6}$

Column (1) shows the OLS estimation of selected by Autometrics. Column (2) shows the IV estimation as the variations of $\mathrm{CO}_{2}$ concentrations have a contemporaneous effect on yield variations and, from the long-run results, we have found that $\mathrm{CO}_{2}$ may also adjust to reach the equilibrium in the climate model. The estimated models pass all diagnostic tests at traditional levels.

The main finding is that only the EC term derived from the technology model maintains its effect on soybean yield when nested with other long run deviations. Much of its effect is in the first year. Therefore, the results obtained from this in-sample

\footnotetext{
${ }^{6}$ In the case of the climate system, we have included the two-lagged ECT in the general unrestricted model as the first lag was not significant.
} 
encompassing test performed by Autometrics suggest that the information content of the technology model in the long-run is such that it dominates the others.

However, the effect of climate variables as well as changes in the use of fertilizers can explain the variations of yields in the short run. Our estimates show that variations on $\mathrm{CO}_{2}$ increase soybean yields. We can note that for the median values of $\mathrm{CO}_{2}$ rises, the short run effect on yield is about $14 \%$, all else equal. However, it is difficult to assume that $\mathrm{CO}_{2}$ concentrations in the atmosphere could increase without an increase in global temperature and a higher intensity, frequency and duration of extreme weather events.

In particular, the estimates show as expected, negative effects of La Niña events, associated with droughts, and cumulated days of high temperature. No effects of El Niño events as well as other weather variables associated with excessive precipitations and floods were found significant. The greater importance of changes in temperature over changes in rainfall on crop yields was also found by Reilly and Schimmelpfennig (2000) and Schlenker and Lobell (2010). An extreme event associated with La Niña episodes decreases yields in $1 \%$ or $2 \%$, while 10 additional days of maximum temperature above $30^{\circ} \mathrm{C}$ during the growing season produce a decrease of $5 \%$.

Although it is difficult to assess how the climate variables of this model will change in the future with local consequences of the global warming, the free ride effect that Argentine soybean yields should be jointly evaluated with the potential effects derived of other climate variables. 
Table 2: Selected equilibrium correction model, 1973-2015

\begin{tabular}{|c|c|c|}
\hline Dependent variable $(\Delta \ln (y))$ & $\begin{array}{c}(1) \\
\text { OLS }\end{array}$ & $\begin{array}{l}(2) \\
\text { IV }\end{array}$ \\
\hline constant & $\begin{array}{c}6.58 \\
(0.91) \\
{[0.00]}\end{array}$ & $\begin{array}{c}6.20 \\
(1.01) \\
{[0.00]}\end{array}$ \\
\hline EC term technology $_{t-1}$ & $\begin{array}{l}-0.87 \\
(0.13) \\
{[0.00]}\end{array}$ & $\begin{array}{l}-0.82 \\
(0.14) \\
{[0.00]}\end{array}$ \\
\hline$\Delta \ln \left(\right.$ fertilizer $_{t}$ & $\begin{array}{c}0.11 \\
(0.05) \\
{[0.02]}\end{array}$ & $\begin{array}{c}0.12 \\
(0.05) \\
{[0.02]}\end{array}$ \\
\hline$N i \widetilde{n} a_{t-1}$ & $\begin{array}{c}-0.01 \\
(0.004) \\
{[0.00]}\end{array}$ & $\begin{array}{c}-0.01 \\
(0.005) \\
{[0.02]}\end{array}$ \\
\hline $\max 30_{t}$ & $\begin{array}{c}-0.005 \\
(0.002) \\
{[0.01]}\end{array}$ & $\begin{array}{c}-0.006 \\
(0.002) \\
{[0.01]}\end{array}$ \\
\hline$\Delta \ln \left(C O_{2}\right)_{t}$ & $\begin{array}{c}31.56 \\
(12.65) \\
{[0.02]}\end{array}$ & $\begin{array}{c}44.48 \\
(17.85) \\
{[0.02]}\end{array}$ \\
\hline$\hat{\sigma}$ & 0.0996 & 0.1024 \\
\hline F test of excluded instruments & & $\begin{array}{c}9.92 \\
{[0.000]}\end{array}$ \\
\hline Sargan test & & $\begin{array}{c}0.927 \\
{[0.819]}\end{array}$ \\
\hline
\end{tabular}

Finally, given that the variations of $\mathrm{CO}_{2}$ have a contemporaneous effect on yield variations in the short-run and given that cointegration results have shown us that this variable may also adjust in the long-run, we reestimated the model using instrumental variables (IV). As instruments, we employ the log difference of the global fossil fuel consumption $^{7}$, the log level of passenger cars and commercial vehicles ${ }^{8}$ and two impulse dummies for 1976 and 1998. According to the Carbon Dioxide Information Analysis Center (CDIAC), hundreds of billions of metric tonnes of carbon have been released into the atmosphere from the consumption of fossil fuels since 1751, leading to a

\footnotetext{
${ }^{7}$ This variable is measured as the global primary energy consumption by fossil fuel source (coal, crude oil and natural gas), measured in terawatt-hours (TWh). Data was obtained from Vaclav Smil (2017). Energy Transitions: Global and National Perspectives \& BP Statistical Review of World Energy.

${ }^{8}$ This variable was obtained from the Motor Vehicle Manufacturers Association of the United States, World Motor Vehicle Data, 1981 Edition; Ward's Communications, Ward's World Motor Vehicle Data 2002; United States Department of Transportation, Bureau of Transportation Statistics, National Transportation Statistics, Table 1-23.
} 
positive correlation between this two variables. The Sargan test also validates the instrumental variables as the null hypothesis that the error term is not correlated with the instruments is not rejected. From the IV estimation, the short run coefficient of $\mathrm{CO}_{2}$ variations increases, but it is not statistically different from the OLS estimation. This result may suggest that $\mathrm{CO}_{2}$ can be taken as given in the soybean yield equilibrium correction model in which the long run relationship is represented by a technological effect.

\section{Final remarks}

Evaluating the effect of climate change on crop yields is a difficult task mainly due to their many different determinants and empirical methodologies followed. As a multidisciplinary topic, many agronomists, meteorologists and other scientists have been largely studying this subject. This paper has contributed to understand the effects of climate change on crop yields using a multivariate econometric model that enables us to evaluate encompassing of different climatic, technological and economic factors that have been suggested in the literature.

We focus on soybean yields in Argentina, the third worldwide largest producer and exporter of this commodity. Using a partial system approach, we study the long run behaviour of soybean yields. In particular, we have measured the effect of global climate change, including the mitigation effects driven by the $\mathrm{CO}_{2}$ fertilization. Other effects coming from new managerial practices and technology innovations are considered as well. Using an automatic algorithm to select variables, Autometrics, we have analyzed encompassing of the different models discriminating long run and short run effects.

Our main results indicate that soybean yields in the long run is mainly dominated by technology innovation variables such as the evolution of no till adoption and the incorporation of new seeds. As short run determinants, we found positive effects associated to the use of standard fertilizers and also from changes in atmospheric $\mathrm{CO}_{2}$ concentration which would suggest a mitigation effect from global warming. However, we also found negative climate effects from periods of droughts associated with La Niña episodes and high temperatures during the growing season of the plant, which should be jointly evaluated when analyzing climate change.

Further research should focus on studying if the technological long run effects on soybean yields is driven by economic or the same climate factors. 


\section{Acknowledgements}

Earlier versions of this paper were presented at the 20th OxMetrics User Conference in London and the First Workshop of the Economics of Climate Change in Buenos Aires in 2018. We would like to thank those who participated in these meetings for valuable comments and suggestions. The usual disclaimer applies. 


\section{References}

Auffhammer, Maximilian, Veerabhadran Ramanathan, and Jeffrey R Vincent 2012. Climate change, the monsoon, and rice yield in India. Climatic Change 111(2), $411-424$.

Auffhammer, Maximilian and Wolfram Schlenker 2014. Empirical studies on agricultural impacts and adaptation. Energy Economics 46, 555-561.

Brouwer, Gordon de and Neil R Ericsson 1998. Modeling inflation in Australia. Journal of Business \& Economic Statistics 16(4), 433-449.

Burke, Marshall and Kyle Emerick 2016. Adaptation to climate change: Evidence from US agriculture. American Economic Journal: Economic Policy 8(3), 106-40.

Chen, Shuai, Xiaoguang Chen, and Jintao Xu 2013. Impacts of climate change on corn and soybean yields in China. AAEA \& CAES Joint Annual Meeting.

Cohn, Avery S, Leah K VanWey, Stephanie A Spera, and John F Mustard 2016. Cropping frequency and area response to climate variability can exceed yield response. Nature Climate Change 6(6), 601.

Doornik, Jurgen A 2008. Encompassing and automatic model selection. Oxford Bulletin of Economics and Statistics 70, 915-925.

Fisher, MA 1925. III. The influence of rainfall on the yield of wheat at Rothamsted. Philosophical Transactions of the Royal Society 213(402-410), 89-142.

Gray, Sharon B, Orla Dermody, Stephanie P Klein, Anna M Locke, Justin M Mcgrath, Rachel E Paul, David M Rosenthal, Ursula M Ruiz-Vera, Matthew H Siebers, and Reid Strellner 2016. Intensifying drought eliminates the expected benefits of elevated carbon dioxide for soybean. Nature Plants 2(9), 16132.

Hendry, David F 2001. Modelling UK inflation, 1875-1991. Journal of Applied Econometrics 16(3), 255-275.

Huang, Haixiao and Madhu Khanna 2010. An econometric analysis of US crop yield and cropland acreage: implications for the impact of climate change. AAEA Annual Meeting, 25-27.

Juselius, Katarina 1992. Domestic and foreign effects on prices in an open economy: The case of Denmark. Journal of Policy Modeling 14(4), 401-428.

Juselius, Katerina 2006. The Cointegrated VAR Model. Methodology and Applications. Oxford: Oxford University Press. 
Lobell, David B and Marshall B Burke 2010. On the use of statistical models to predict crop yield responses to climate change. Agricultural and Forest Meteorology 150(11), $1443-1452$.

Lobell, David B, Marshall B Burke, Claudia Tebaldi, Michael D Mastrandrea, Walter P Falcon, and Rosamond L Naylor 2008. Prioritizing climate change adaptation needs for food security in 2030. Science 319(5863), 607-610.

Lobell, David B, Wolfram Schlenker, and Justin Costa-Roberts 2011. Climate trends and global crop production since 1980. Science, 1204531.

Magrin, Graciela O, María I Travasso, and Gabriel R Rodríguez 2005. Changes in climate and crop production during the 20th century in Argentina. Climatic Change 72(1-2), 229-249.

Morton, Douglas C, Ruth S DeFries, Yosio E Shimabukuro, Liliana O Anderson, Egidio Arai, Fernando del Bon Espirito-Santo, Ramon Freitas, and Jeff Morisette 2006. Cropland expansion changes deforestation dynamics in the southern Brazilian Amazon. Proceedings of the National Academy of Sciences 103(39), 14637-14641.

Nocelli Pac, Santiago 2017. Evolution of no till adoption in argentina. Report, AAPRESID.

Nordhaus, William D 2013. The climate casino: Risk, uncertainty, and economics for a warming world. Yale University Press.

Pretis, Felix 2017. Exogeneity in climate econometrics.

Reilly, John and David Schimmelpfennig 2000. Irreversibility, uncertainty, and learning: portraits of adaptation to long-term climate change. Climatic Change 45(1), 253-278.

Schlenker, Wolfram and David B Lobell 2010. Robust negative impacts of climate change on African agriculture. Environmental Research Letters 5(1), 014010.

Schlenker, Wolfram and Michael J Roberts 2009. Nonlinear temperature effects indicate severe damages to us crop yields under climate change. Proceedings of the National Academy of Sciences 106(37), 15594-15598.

Smith, J Warren 1914. The effect of weather upon the yield of corn. Monthly Weather Review 42(2), 78-92.

Thomasz, Esteban Otto, María Teresa Casparri, Ana Silvia Vilker, Gonzalo Rondinone, and Miguel Fusco 2016. Medición económica de eventos climáticos extremos 
en el sector agrícola: el caso de la soja en Argentina. Revista de Investigación en Modelos Financieros 4.

Welch, Jarrod R, Jeffrey R Vincent, Maximilian Auffhammer, Piedad F Moya, Achim Dobermann, and David Dawe 2010. Rice yields in tropical/subtropical Asia exhibit large but opposing sensitivities to minimum and maximum temperatures. Proceedings of the National Academy of Sciences 107(33), 14562-14567.

Wheeler, Timothy R, Peter Q Craufurd, Richard H Ellis, John R Porter, and PV Vara Prasad 2000. Temperature variability and the yield of annual crops. Agriculture, Ecosystems \& Environment 82(1-3), 159-167. 


\section{A. Appendix}

Table A1. Unit root tests

\begin{tabular}{|c|c|c|c|c|c|c|c|}
\hline Variable & trend & $k$ & $\mathrm{ADF}$ & $b$ & $\mathrm{PP}$ & $b$ & KPSS \\
\hline $\ln (y)$ & yes & 0 & $-6.74^{* * *}$ & 2 & $-6.74^{* * *}$ & 2 & 0.06 \\
\hline temp & yes & 0 & $-5.71^{* * *}$ & 4 & $-5.67^{* * *}$ & 3 & 0.05 \\
\hline $\ln \left(\mathrm{CO}_{2}\right)$ & yes & 0 & -0.69 & 4 & -0.54 & 5 & $0.18^{* *}$ \\
\hline $\max 30$ & no & 0 & $-6.25^{* * *}$ & 2 & $-6.27^{* * *}$ & 3 & 0.27 \\
\hline$A D 2 S E$ & no & 0 & $-5.77^{* * *}$ & 2 & $-5.73^{* * *}$ & 2 & 0.22 \\
\hline$N i \widetilde{n} a$ & no & 0 & $-4.62^{* * *}$ & 1 & $-4.65^{* * *}$ & 2 & 0.12 \\
\hline $\ln ($ seeds $)$ & yes & 0 & $-8.55^{* * *}$ & 4 & $-8.30^{* * *}$ & 4 & 0.08 \\
\hline notill & yes & 1 & -1.78 & 4 & -2.69 & 5 & $0.19^{* *}$ \\
\hline $\ln ($ fertilizer $)$ & yes & 0 & -2.88 & 0 & -2.88 & 9 & $0.11^{* * *}$ \\
\hline $\ln \left(p^{\text {fertilizer }}\right)$ & yes & 0 & $-3.19^{*}$ & 1 & $-3.35^{*}$ & 4 & $0.18^{* *}$ \\
\hline $\ln \left(p^{\text {soybean }}\right)$ & yes & 2 & -0.98 & 0 & -2.73 & 4 & $0.18^{* *}$ \\
\hline$E C T^{\text {climate }}$ & no & 0 & $-5.75^{* * *}$ & 1 & $-5.76^{* * *}$ & 2 & 0.24 \\
\hline$E C T^{\text {technology }}$ & no & 0 & $-6.23^{* * *}$ & 1 & $-6.23^{* * *}$ & 0 & 0.16 \\
\hline$E C T 1^{\text {prices }}$ & no & 0 & $-5.71^{* * *}$ & 2 & $-5.71^{* * *}$ & 1 & 0.08 \\
\hline$E C T 2^{\text {prices }}$ & no & 0 & $-5.25^{* * *}$ & 21 & $-5.80^{* * *}$ & 15 & 0.16 \\
\hline$\Delta \ln (y)$ & no & 1 & $-7.66^{* * *}$ & 16 & $-20.12^{* * *}$ & 20 & 0.32 \\
\hline$\Delta t e m p$ & no & 6 & $-5.42^{* * *}$ & 41 & $-33.39^{* * *}$ & 9 & 0.29 \\
\hline$\Delta \ln \left(\mathrm{CO}_{2}\right)$ & no & 0 & $-5.64^{* * *}$ & 1 & $-5.65^{* * *}$ & 6 & 0.10 \\
\hline$\Delta \max 30$ & no & 1 & $-7.96^{* * *}$ & 13 & $-23.03^{* * *}$ & 8 & 0.11 \\
\hline$\triangle A D 2 S E$ & no & 1 & $-9.31^{* * *}$ & 20 & $-20.62^{* * *}$ & 28 & 0.31 \\
\hline$\Delta N i \tilde{n} a$ & no & 1 & $-6.91^{* * *}$ & 8 & $-14.55^{* * *}$ & 7 & 0.10 \\
\hline$\Delta \ln ($ seeds $)$ & no & 1 & $-8.79^{* * *}$ & 2 & $-9.77^{* * *}$ & 1 & 0.14 \\
\hline$\Delta$ notill & no & 0 & $-3.70^{* * *}$ & 2 & $-3.64^{* * *}$ & 4 & $0.42^{*}$ \\
\hline$\Delta \ln ($ fertilizer $)$ & no & 0 & $-7.10^{* * *}$ & 5 & $-7.25^{* * *}$ & 6 & 0.15 \\
\hline$\Delta \ln \left(p^{\text {fertilizer }}\right)$ & no & 1 & $-6.22^{* * *}$ & 17 & $-6.58^{* * *}$ & 14 & 0.18 \\
\hline$\Delta \ln \left(p^{\text {soybean }}\right)$ & no & 1 & $-8.71^{* * *}$ & 22 & $-6.47^{* * *}$ & 16 & 0.17 \\
\hline$\Delta E C T^{\text {climate }}$ & no & 2 & $-6.69^{* * *}$ & 41 & $-22.58^{* * *}$ & 20 & 0.33 \\
\hline$\Delta E C T^{\text {technology }}$ & no & 1 & $-7.61^{* * *}$ & 15 & $-20.96^{* * *}$ & 12 & 0.26 \\
\hline$\Delta E C T 1^{\text {prices }}$ & no & 1 & $-7.87^{* * *}$ & 22 & $-14.87^{* * *}$ & 16 & 0.33 \\
\hline$\Delta E C T 2^{\text {prices }}$ & no & 1 & $-7.29^{* * *}$ & 19 & $-16.41^{* * *}$ & 21 & 0.27 \\
\hline
\end{tabular}

Note: $k=$ lag length selected by SIC, $b=$ bandwidth using Bartlett kernel. *, ${ }^{* *} \mathrm{y}{ }^{* * *}$ indicate significance at the $10 \%, 5 \%$ and $1 \%$ level, respectively. ADF $=$ Augmented Dickey Fuller, PP $=$ Phillips-Perron, KPSS $=$ KwiatkowskiPhillips-Schmidt-Shin. A constant and a trend were included for level variables that exhibited a trend behaviour, otherwise only a constant was considered. 
Table A2. Climate model: cointegration analysis, 1973-2015.

\begin{tabular}{cccc}
\hline \hline$r$ & Eigenvalue & Trace & p-value \\
\hline 0 & 0.38 & 43.12 & 0.046 \\
1 & 0.31 & 22.89 & 0.112 \\
2 & 0.15 & 6.94 & 0.361
\end{tabular}

For $r=1$

Unrestricted adjustment coefficients $(\alpha)$

\begin{tabular}{lcc}
\hline Variable & Coeff. & S.E. \\
\hline $\ln (y)$ & -0.21 & 0.09 \\
$\ln ($ temp $)$ & -0.24 & 0.07 \\
$\ln \left(\mathrm{CO}_{2}\right)$ & -0.002 & 0.001
\end{tabular}

Restricted eigenvectors $(\beta)$

\begin{tabular}{lcc}
\hline Variable & Coeff. & S.E. \\
\hline $\ln (y)$ & 1.00 & - \\
$\ln ($ temp $)$ & 2.34 & 0.75 \\
$\ln \left(\mathrm{CO}_{2}\right)$ & -11.94 & 2.75 \\
trend & - & -
\end{tabular}

LR test: $0.41 ; p$-value $=0.52$

Note: the $\operatorname{VAR}(2)$ model unrestrictedly includes $N i \widetilde{n} a$ and $\max 30$.

Table A3. Technological model: cointegration analysis, 1973-2015.

\begin{tabular}{cccc}
\hline \hline$r$ & Eigenvalue & Trace & p-value \\
\hline 0 & 0.65 & 70.73 & 0.00 \\
1 & 0.36 & 25.24 & 0.06 \\
2 & 0.13 & 5.76 & 0.50
\end{tabular}

For $r=1$

Restricted adjustment coefficients $(\alpha)$

\begin{tabular}{lcc}
\hline Variable & Coeff. & S.E. \\
\hline $\ln (y)$ & -0.99 & 0.22 \\
$\ln ($ no - till $)$ & - & - \\
$\ln ($ seeds $)$ & - & -
\end{tabular}

Restricted eigenvectors $(\beta)$

\begin{tabular}{lcc}
\hline Variable & Coeff. & S.E. \\
\hline $\ln (y)$ & 1.00 & - \\
$\ln ($ no - till $)$ & -0.002 & 0.001 \\
$\ln ($ seeds $)$ & -0.06 & 0.03 \\
trend & - & -
\end{tabular}

LR test: $3.34 ; p$-value $=0.65$

Note: the VAR(2) model unrestrictedly includes two impulse dummies for 2012 and 2013. 
Table A4. Prices model: cointegration analysis, 1973-2014.

\begin{tabular}{lccc}
\hline \hline$r$ & Eigenvalue & Trace & p-value \\
\hline 0 & 0.60 & 64.15 & 0.00 \\
1 & 0.37 & 25.11 & 0.06 \\
2 & 0.12 & 5.35 & 0.56
\end{tabular}

For $r=2$

Restricted adjustment coefficients $(\alpha)$

\begin{tabular}{lcccc}
\hline Variable & \multicolumn{2}{c}{ Vector 1} & \multicolumn{2}{c}{ Vector 2} \\
& Coeff. & S.E. & Coeff. & S.E. \\
\hline $\ln (y)$ & -0.77 & 0.17 & 0.46 & 0.17 \\
$\ln \left(p^{\text {fertilizer }}\right)$ & - & - & -0.67 & 0.20 \\
$\ln \left(p^{\text {soybean }}\right)$ & 0.36 & 0.11 & - & -
\end{tabular}

Restricted eigenvectors $(\beta)$

\begin{tabular}{lcccc}
\hline Variable & \multicolumn{2}{c}{ Vector 1} & \multicolumn{2}{c}{ Vector 2} \\
& Coeff. & S.E. & Coeff. & S.E. \\
\hline $\ln (y)$ & 1.00 & - & - & - \\
$\ln \left(p^{\text {fertilizer }}\right)$ & 0.82 & 0.12 & 1.00 & - \\
$\ln \left(p^{\text {soybean }}\right)$ & -1.16 & 0.19 & -1.36 & 0.13 \\
trend & -0.02 & 0.003 & -0.01 & 0.003
\end{tabular}

LR test: $0.93 ; p$-value $=0.33$

Note: the VAR(2) model includes an unrestricted dummy for 1973. 